\title{
Impaired Cardiac Vagal Tone in Patients with Major Depressive Disorder
}

\author{
Choudhury Rifat Jahan ${ }^{1}$, Shelina Begum ${ }^{2}$, Sultana Ferousi $^{3}$, Md. Moyeen Uddin ${ }^{4}$.
}

\begin{abstract}
Background: Altered cardiovascular autonomic nerve function with impaired autonomicl balance is found in Major Depressive Disorder(MDD). Objective: To assess some time domain measures of Heart Rate Variability (HRV) in MDD patients to observe their autonomic nerve function status.. Methods: This cross sectional study was conducted in the Department of Physiology, Bangabandhu Sheikh Mujib Medical University (BSMMU), Dhaka, during 2011 on 60 patients of both sexes with Major Depressive disorder (MDD) aged 20-50 years. They were further subdivided into 30 drug naïve and 30 patients treated with anti depressive drug. Age, sex and BMI matched 30 apparently healthy subjects were control. The HRV parameters were recorded by 4 active channels, Polyrite-D. For statistical analysis ANOVA, independent sample t-test, were performed. Result: Mean R-R interval, SDNN,RMSSD ,PNN50\%, NN50\% were found significanty lower but heart rate was significantly higher in all MDD patients of both group compared to control.No significant differences were found in these parameters between treated and recently diagnosed patient. Conclusion: Cardiac autonomic nerve function was impaired in MDD patient which was characterized by reduced vagal tone. Antidepressive medication may not have any effect on impaired autonomic function in MDD.
\end{abstract}

Key words: HRV, MDD, SDNN, RMSSD, heart rate

J Bangladesh Soc Physiol. 2015, December; 10(2): 41-45

For Authors Affiliation, see end of text.

http://www.banglajol.info/index.php/JBSP

\section{Introduction}

D epression is one of the most common problems encountered in the practice of Psychiatric medicine affecting about 121 million people worldwide ${ }^{1}$ .It is characterized by sadness, indifference, apathy or irritability and usually associated with changes in sleep patterns, appetite and weight, motor agitation or retardation, fatigue, impaired concentration and decision making, feeling of shame or guilt and thoughts of death or dying. It is a morbid sadness which affects both mind and body ${ }^{2}$.

Received June 2015;

Accepted August 2015
The prevalence of Depression in Bangladesh is $2.9 \%$ for males and $11.6 \%$ in females and the male-female ratio is $1: 2.63$. Due to adverse social circumstances, the incidence of Depression is more in females. Onset may be at any age; most often between 25-44 years 3,4

Epidemiological studies reported greater cardiovascular mortality in cardiac patients with depression than without depression ${ }^{5}$ because of autonomic dysregulation as a result of depressive disorders .Increased sympathetic and reduced vagal activity are strongly involved in the patho-physiology of arrhythmia, sudden cardiac death, myocardial infarction, congestive cardiac failure ${ }^{6}$. 
Time domain variables of HRV such as include mean $\mathrm{R}-\mathrm{R}$ interval and mean heart rate, the standard deviation of the NN interval(SDNN), the square root of the mean squared difference of successive NN interval(RMSSD), NN50\% and PNN50\% in general reflect cardiac vagal activity $^{7}$.Lower Mean R-R interval and Higher heart rate were observed in MDD patients when compared to that of healthy control ${ }^{8-13}$. Where as some investigators reported lower heart rate in MDD patients in comparison to controls ${ }^{14}$.In addition, lower values of SDNN, RMSSD, PNN50\% were also reported in MDD patients $10,14,15$

Because of conflicting result on autonomic functions in MDD patients this study aimed to evaluate the impact of depression as well as effects of anti depressive medication on cardiac autonomic nerve function by measuring time domain variable of HRV in MDD patient.

\section{Methods}

This cross sectional study was carried out on 60 MDD patients aged 20-50 years in the Department of Physiology, Bangabandhu Sheik Mujib Medical university (BSMMU) from $1^{\text {st }}$ January to $30^{\text {th }}$ December 2011. Age, sex and BMI matched 30(male 10 female 20 female) subjects selected as control. MDD patients were further subdivided equally into 30 drug naïve(12 male 18 female), \& 30(male 14 female 16) treated with anti depressive medication. The patients were selected from the Department of Psychiatry, BSMMU and the controls were selected from community of Dhaka city. All the subjects were free from heart disease, hypertension, diabetes mellitus, chronic kidney disease, other psychiatric disorders and smoking. The study protocol was approved by ethical review committee of BSMMU.

After selection, the subject was thoroughly informed about the aim, objectives and detail procedure of the study before examination and collection of blood sample. Written informed consent was taken from them. To prepare for RV test the subjects were advised to finish their meal by 9:00 pm on previous night, to remain free from any physical or mental stress, not to take any drugs affecting central nervous system and to have a good sleep at night before the examination day. The subjects were advised to avoid tea or coffee at breakfast and to report the Autonomic Nerve Function test Laboratory in the department of Physiology of BSMMU between 9.00 to11.00 a.m. on the day of examination. Then after a thorough physical examinations pulse BP height, weight, BMI were recorded in a data schedule. The subject was in rest in supine position for 15-20 minutes in a cool and calm environment. During this period subject was advised not to talk, eat or drink and also not to perform any physical or mental activity, even sleep. Then all preparations for recording of the Heart rate variability parameters were made by connecting the channel of ECG of the polyrite $\mathrm{D}$ to the electrode placed on patients left leg..ECG data was recorded using only lead II. A 5 minutes ECG recording was taken in supine position. Data of time domain parameters of HRV (R-R interval SDNN,RMSSD, NN50\%, PNN50\%) were obtained by HRV software analysis of the 5 minutes ECG recording.. Data were expressed as mean $\pm \mathrm{SE}$. As test of significance one way ANOVA, student's unpaired t-test were used.

\section{Results}

In drug naïve and treated MDD patients the mean resting pulse rate, SBP \& DBP were significantly $(\mathrm{p}<0.001)$ higher in comparison to control. (Table I). Again, R-R interval SDNN,RMSSD, NN50\%, PNN50\% were found significantly $(\mathrm{p}<0.001)$ lower but mean heart rate was $(\mathrm{p}<0.001)$ higher in all MDD patients in both drug naive and medicated patients than control(Table II). Again, no significant differences were observed when compared all these parameters between two groups of patients. Correlation analysis of these parameters with duration of disease was done. Results were not shown as the results were not significant. 
Table I: Resting Pulse rate and BP in different groups ( $\mathrm{n}=90)$

\begin{tabular}{lccc}
\hline Variables & $\begin{array}{c}\text { Control } \\
(\mathrm{n}=30)\end{array}$ & $\begin{array}{c}\text { Drug naïve MDD } \\
(\mathrm{n}=30)\end{array}$ & $\begin{array}{c}\text { Treated MDD } \\
(\mathrm{n}=30)\end{array}$ \\
\hline Pulse & $74 \pm 1.42$ & $86 \pm 1.25^{* * *}$ & $85 \pm 1.17^{* * *}$ \\
(beat/min) & $(60-90)$ & $(70-100)$ & $(72-98)$ \\
SBP & $112 \pm 1.91$ & $122 \pm 1.77^{* * *}$ & $120 \pm 2.00^{* * *}$ \\
$(\mathrm{~mm}$ of Hg) & $(95-135)$ & $(100-135)$ & $(100-140)$ \\
DBP & $70 \pm 1.49$ & $76 \pm 1.27^{* *}$ & $74 \pm 1.16$ \\
$(\mathrm{~mm}$ of Hg) & $(60-90)$ & $(60-90)$ & $(60-85)$ \\
\hline
\end{tabular}

Data were expressed as Mean \pm SE. Statistical analysis were done by One-way ANOVA and Independent sample t-test $\mathrm{SBP}=$ Systolic blood pressure. $\mathrm{DBP}=$ Diastolic blood pressure. $(* * *=\mathrm{p}<0.001 \quad * *=\mathrm{p}<0.01$, Control vs patients).

Table II : Time domain measures of HRV in different groups ( $\mathrm{n}=90)$

\begin{tabular}{lccc}
\hline Groups & $\begin{array}{c}\text { Control } \\
(\mathrm{n}=30)\end{array}$ & $\begin{array}{c}\text { Drug naïve MDD } \\
(\mathrm{n}=30)\end{array}$ & $\begin{array}{c}\text { Treated MDD } \\
(\mathrm{n}=30)\end{array}$ \\
\hline Mean heart rate & $76 \pm 1.17$ & $87 \pm 2.29^{* * *}$ & $86 \pm 1.81^{* * *}$ \\
(beat/min) & $(65-88)$ & $(62-110)$ & $(68-100)$ \\
Mean R-R & $0.79 \pm 0.01$ & $0.71 \pm 0.02^{* *}$ & $0.71 \pm 0.01^{* * *}$ \\
interval(sec) & $(0.68-0.91)$ & $(0.55-0.97)$ & $(0.60-0.88)$ \\
SDNN & $77.28 \pm 2.59$ & $47.22 \pm 3.88^{* * *}$ & $44.54 \pm 3.59^{* * *}$ \\
(ms) & $(47.40-97.40)$ & $(22.3-96.49)$ & $(17.51-87.47)$ \\
RMSSD & $34.30 \pm 0.80$ & $21.35 \pm 2.05^{* * *}$ & $24.08 \pm 2.27^{* * *}$ \\
$(\mathrm{~ms})$ & $(22.54-40.23)$ & $(10.65-40.39)$ & $(12.26-43.44)$ \\
NN50 & $72 \pm 5.44$ & $34 \pm 6.6^{* * *}$ & $23 \pm 5.5^{* * * *}$ \\
$(\%)$ & $(20-138)$ & $(1-153)$ & $(1-123)$ \\
PNN50 & $23.0 \pm 2.48$ & $10.2 \pm 2.18^{* * *}$ & $11.49 \pm 1.39^{* * *}$ \\
$(\%)$ & $(7.9-50.4)$ & $(.02-28.4)$ & $(0.9-28.8)$ \\
\hline
\end{tabular}

Data were expressed as Mean \pm SE. Figures in parentheses indicate ranges.Statistical analysis were done by One-way ANOVA and Independent sample t-test .R-R = Interval between successive QRS complex (sec) . $\mathrm{SDNN}=$ Standard deviation of NN interval, $\mathrm{RMSSD}=$ Square root of mean squared Differences between adjacent $\mathrm{NN}$ intervals, $\mathrm{NN} 50 \%=$ number of interval differences of successive $\mathrm{NN}$ intervals greater than $50 \mathrm{~ms}, \mathrm{PNN} 50 \%=$ number of R-R interval differing by $>50 \mathrm{~ms}$ from adjacent intervals divided by the total number of all R-R intervals, ms $=$ millisecond, $\left(\right.$ control vs MDD $\left.{ }^{* * *} \mathrm{p}<0.001,{ }^{* *} \mathrm{p}<0.01,{ }^{*} \mathrm{p}<0.05\right)$. 


\section{Discussion}

In the present study, the time domain parameters of HRV in patients with Major Depressive Disorder were analyzed to assess their cardiac autonomic activity. Moreover the effect of treatment with anti depressive medication was also observed.

The resting pulse rate, SBP, DBP were significantly higher in both drug naïve and medicated MDD patients except DBP in treated patients when compared with control. These observations were similar to Udupa et al. ${ }^{13}$ whereas opposite results were reported by other investigators ${ }^{8,16}$.

The significant lower R-R interval, SDNN, RMSSD, PNN50\%, NN50\% in all MDD patients in this study is comparable to other investigators. ${ }^{8,11-13,15,16}$ Though some researchers found similar trends but it was not statistically significant ${ }^{9,10,14,17}$ In the present analysis, no significant difference in all these HRV parameters were found between drug naïve and treated patients of MDD. The observation of present analysis suggest cardiac vagal tone was decreased in MDD patients. In addition, effect of antidepressive medication is not apparent on compromised cardiac autonomic function in MDD patients.

Literatures on reduced HRV in MDD patients suggested that, vagas acts as control center for attention, co-ordination, emotion, communication which are altered in depression ${ }^{18}$.

The exact mechanism of poor vagal activity in MDD patients is not evident.Moreover, antidepressive medication mostly affect the serotonergic system and which has no association with vagal center. Therefore this treatment may not improve cardiac parasympathetic function.

\section{Conclusion}

This study concludes that decreased autonomic function characterized by reduced cardiac vagal tone occurred in MDD patients and it remained unaffected by treatment with anti depressive drug.

\section{Conflict of interest: None}

\section{Author affiliations}

1. Choudhury Rifat Jahan, Assistant Professor(CC), Department of Physiology, ParkView Medical College, Taltola, Sylhet. Email:rifatziyad@gmail.com.

2. Shelina Begum, Professor, Chairman, Department of Physiology, Bangabandhu Sheikh Mujib Medical University (BSMMU), Bangladesh.Email:shelina 1982@gmail.com.

3. Sultana Ferdousi,Associate Professor, Department of Physiology, Bangabandhu Sheikh Mujib Medical University(BSMMU), Bangladesh. Email:sferdousi ratna@gmail.com.

4. Md.Moyeen Uddin, Assistant Professor, Medicine, Sylhet Osmani Medical College, Email:umoyeen (a)email.com

*For correspondence

\section{References}

1. WHO Mental health.[internet].2011[cited 2011 June 6]. Available from: http:// www. who. int/ mental_health/management/ depression/definition.

2. Muhit MA, Maruf MM,Ahmed H, Alam MT.Depression and physical illness:an update.Ban Med J.2011;40(1):53-57.

3. Rahim DAKMA, Ali SMK and Ali MSM. Nutritional status of depressive patients: A study in an urban hospital, Bangladesh. The Orion Med J. 2003; 14:4749.

4. Sharpe MC, Lawrie SM. Medical Psychiatry. In: College NR, Walker BR, Ralston SH, editors. Davidson's Principles and Practice of Medicine. Edinburgh: Churchil Livingstone; 2002. 230-251.

5. CarneyRM, Rich MW, Tevelde A, Saini J, Clark K, Jaffe AS. Major depressive disorder in coronary artery disease. Am J Cardiol. 1987; 60:1273 -1275.

6. Kleiger RE, Stein PK, Bosner MS, Rottman JN. Time domain measurements of heart rate variability. Cardiol Clin. 1992; 10(3): 487-498.

7. Task Force of the European society of cardiology and the North American society of pacing and electrophysiology, Heart Rate Variability. standards of measurement, physiological interpretation and clinical use. Circulation. 1996; 93: 1043-1065.

8. Agelink MW, Boz H,Andrich J. Relationship between major depression and heart rate variability. Clinical 
consequences and implications for antidepressive treatment. Psychiatry res.2002;113: 139-149.

9. Bar KJ, Greiner W, Jochum T, Friedrich M, Wagner $\mathrm{G}$, Sauer H. The influence of major depression and its treatment on heart rate variability and a pupillary light reflex parameters. J Affec Disord. 2004; 82: 245-252.

10. Kooy KGVD, Hout HPJV, Marwijk HWJV, Hann MD, Stehouwer CDA, Beekman ATF. Differences in heart rate variability between depressed and non depressed elderly. Int J Geriatr Psychiatry. 2006; 21:147-150.

11. Koschke M, Boettger MK, Schulz S, Berger S, Terhaar J, Voss A, Yeragani VK, Bär KJ. Autonomy of autonomic dysfunction in major depression. Psychosom Med. 2009; 71: 852-860.

12. Nashoni E, Aravot D, Aizenberg D, Sigler M, Zalsman G, Strasberg B, Imbar S, Weizman A. Heart rate variability in patients with major depression. Psychosomatics. 2004; 45: 129-134.

13. Udupa K, Sathyaprabha TN, Thirthalli J, Kishore KR, Lavekar GS, Raju TR, Gangadhar BN. Alteration of cardiac autonomic functions in patients with major depression: A study using heart rate variability measures. J Affect disord. 2007; 100: 137-141.

14. Licht CMM, Genus EJCD, Zitman FG, Hoogendijk WJG, Dyck RV, Penninx BWJH. Association between
Major depressive disorder and Heart rate variability in the Netherlands study of depression and anxiety(NESDA). Arch Gen Psychiatry. 2008;65(12):1358-1367.

15. Kim CK, Bartholomew BA, Marsh M, Dicken T, Smoller SW, Curb D, Oberman A, Hsia J, Gardin J, Wong ND, Barton B, McMahan, Sheps DS. Depressive Symptoms and HRV in postmenopausal women. Arch Intern Med. 2005; 165:1239-1244.

16. Moser M, Lehofer M, Saric RH, Mcleod DR, Hildbrandt G, Voica M, Steinbrenner B, Leibmann P, Zapotoczky G. Increased heart rate in depressed subjects inspite of unchanged autonomic balance? J Affect Disord. 1998; 48:115-124.

17. Sayar K, Gulec H, Gokce M, Ismail AK.Heart rate variability in depressed patients. Bull of Clin Psychopharmacol. 2002; 12(3):130-133.

18. Rush AJ,George MS,SackeimHA.Vagus nerve stimulation for treatment of resistant depression. 2000:47:276-286.

19. Veith RC, Lewis N, Linares OA, Barnes RF, Raskind MA, Villacres EC, Murburg MM, Ashleigh EA, Castillo S, Peskind ER, Pascualy M, Halter JB. Sympathetic nervous system activity in Major Depression. Arch Gen Psychiatry. 1994; 51: 411-422. 